DOI: 10.4274/jarem.galenos.2019.2620

J Acad Res Med 2020;10(2):192-4

\title{
The Phenomenon of Acute Renal Failure in Patients with Chronic Use of Wild Tobacco
}

\author{
(1) Serhat Soylu, (1) Ümran Yaman, (1) Ülkü Aygen Türkmen, (ㄷ) Illkay Anaklı \\ University of Health Sciences Turkey, Gaziosmanpaşa Training and Research Hospital, Clinic of Anesthesia and Reanimation, İstanbul, Turkey \\ Cite this article as: Soylu S, Yaman Ü, Türkmen ÜA, Anaklı İ. The Phenomenon of Acute Renal Failure in Patients with Chronic Use of Wild Tobacco. \\ J Acad Res Med 2020;10(2):192-4
}

\begin{abstract}
In patients with acute renal failure (ARF), the differential diagnosis may be more difficult than expected. Especially in young adults without additional diseases, it may not be considered in the diagnosis that an ARF can develop on the basis of chronic renal failure (CRF). In this case, ARF developed on the basis of CRF was presented in the light of literature in a young male patient who presented to the emergency department with ARF and who used chronic wild tobacco in his anamnesis.
\end{abstract}

Keywords: Acute renal failure, chronic renal failure, wild tobacco, Nicotiana Rustica Linn

\section{INTRODUCTION}

Wild tobacco (Nicotina Rustica Linn) is a smokeless tobacco used in our country, especially in the southeastern and eastern Mediterranean region, in place of cigarettes or with cigarettes. It is used by placing it in the oral mucosa (1). Chronic use of wild tobacco has been shown to cause many pathologies including oral mucosa cancers and respiratory problems in the long term (2). It has also been shown that blood pressure and heart rate increase in a short time after taking wild tobacco (3). Acute changes in the body after wild tobacco can reveal the underlying pathologies. In this case, acute kidney damage after the use of wild tobacco showed us that the patient had an undiagnosed chronic kidney failure.

\section{CASE PRESENTATION}

A 28-year-old male patient was admitted to the emergency room with respiratory distress and abdominal pain and on his first physical examination he was tachypneic (respiratory rate: 40/minute), hypertensive [tension (TA): 180/100 $\mathrm{mmHg}$ ] and agitated. The blood gas taken under mask oxygen ( $6 \mathrm{~L} /$ minute) in the emergency room is determined to be $\mathrm{pH}: 7.22, \mathrm{pCO}_{2}: 27$ $\mathrm{mmHg}, \mathrm{pO}_{2}: 36 \mathrm{mmHg}, \mathrm{SO}_{2}$ : 49\%, Lac: $1.3 \mathrm{mmol} 1 / \mathrm{L}, \mathrm{HCO}_{3}: 11$ $\mathrm{meq} / \mathrm{L}, \mathrm{BE}:-15 \mathrm{mmol} \mathrm{I} / \mathrm{L}$. It has been decided that the patient who was consulted will be interned in the intensive care unit. After being taken to intensive care, the patient was observed to be $\mathrm{SpO}_{2}$ : 50\% under $3 \mathrm{~L} /$ minute mask oxygen and was intubated orotracheal and began to support invasive mechanical ventilation. While in volume control mode, PEEP was set to $8 \mathrm{~cm} \mathrm{H} \mathrm{H}_{2} \mathrm{O}$ and $\mathrm{FiO}_{2}$ 0.6. It was learned from the relatives of the patient that there was an increasingly severe respiratory distress in the past month, and he had applied to the emergency department several times. He had also swelling (like edema) on his foot recently and this situation regressed spontaneously. In the interrogation made in terms of substance use, it was found that the patient was a chronic wild tobacco (Nicotina Rustica Linn) user and chewed the wild tobacco before applying to the emergency room. Biochemistry

ORCID IDs of the authors: S.S. 0000-0003-3886-5424; Ü.Y. 0000-0001-8525-017X; Ü.A.T. 0000-0002-7280-6420; I.A. 0000-0002-0403-4860. 
care follow-up, there was a decrease in the biochemistry values examined under CVVHDF (urea: $272 \mathrm{mg} / \mathrm{dL}$, creatinine: $16.89 \mathrm{mg} /$ $\mathrm{dL}$.) In the SIMV-P mode as a result of arteriel blood gas, $\mathrm{FiO}_{2}$ : 0.4, Ph: 7.34, $\mathrm{pO}_{2}: 58 \mathrm{mmHg}, \mathrm{PcO}_{2}: 35 \mathrm{mmHg}, \mathrm{SO}_{2}: 90 \%, \mathrm{BE}:$ $-5 \mathrm{mmol} / \mathrm{L}$. On the second day of intensive care follow-up, the patient's anuria continued. The patient's procalcitonin value was $19 \mathrm{ng} / \mathrm{mL}$ and piperacillin-tazobactam, moxifloxacin and linezolid treatment was started by the infectious disease consultant. Urea: $29 \mathrm{mg} / \mathrm{dL}-1$, creatinine: $2.07 \mathrm{mg} / \mathrm{dL}-1$ decreased in the third day of follow-up (Table 1). However, due to the absence of urine output, he was consulted with internal medicine specialist. With the recommendation of internist parathyroid hormone level was requested and parathyroid ultrasound was performed upon high results (parathormon: $412 \mathrm{pg} / \mathrm{dL}$, normal values: 12-88 pg/ $\mathrm{mL}$ ). However, a pathological lesion was not found. The patient was consulted to the nephrology clinic and was diagnosed with ARF, which developed on the basis of chronic kidney failure. The patient was extubated on the $7^{\text {th }}$ day of hospitalization. The patient was transferred to the another hospital to be able to start a routine dialysis program. Our patient, who was a foreign national, remained in our follow-up only for one day after being extubated, and no communication could be established after he was referred to the another hospital and therefore no written consent could be obtained.

\section{DISCUSSION}

Although chronic renal failure occurs in older populations with comorbid diseases, it can also be detected in younger patients admitted to hospital in an ARF status. In young patients admitted to hospital with ARF, CRF is not usually considered (4).

The absence of a history of additional disease in the anamnesis highlights conditions such as intoxication. There are many cases in the literature about ARF as a result of intoxication $(5,6)$. In our case, the fact that the patient was a user of chronic wild tobacco (Nicotiana Rustica Linn) and chewed wild tobacco before applying to the emergency room did not make us think about the diagnosis of chronic renal failure. It has been found that chronic marash powder abuse is mostly associated with oral cavity lesions (3). Although there is no correlation between chronic wild tobacco and ARF, Sucakli et al. (7) found that carotis intima media thickness increased compared to those who did not use it, and this caused systolic and diastolic blood pressure elevation. On the other

Table 1. Creatinine values under continuous venovenous hemodiafiltration in patient's intensive care follow-up

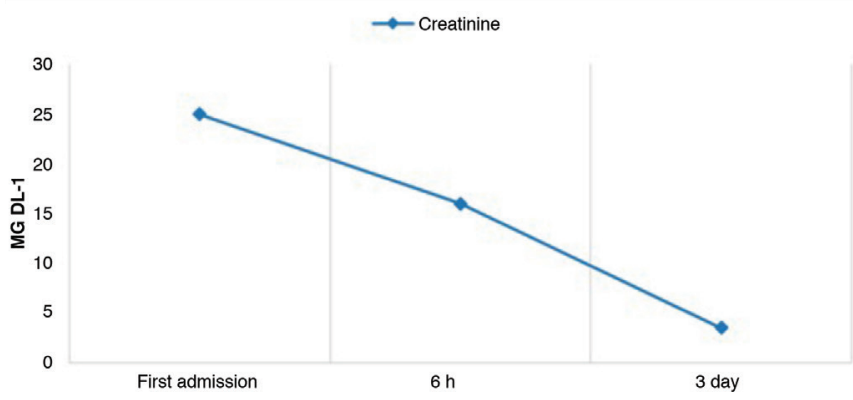


hand, Keten et al. (3) measured systolic-diastolic blood pressures and heart rate at 5, 10, 15, and 20 minutes after the use of wild tobacco and found that wild tobacco significantly increased both blood pressure and heart rate (4). Tobacco products have also been shown to increase the risk of developing chronic kidney failure $(8,9)$. In the light of this information, we would like to draw attention to the fact that wild tobacco may be effective in the development of ARF on the basis of chronic renal failure.

The diagnosis of CRF was made after anamnesis, clinical observation, and consultation with the nephrology clinic. In the patient's history, especially in the last month, episodes of respiratory distress and intermittent bilateral lower limb edema have suggested an underlying CRF clinical picture. Serious anemia (Hgb: $4.7 \mathrm{~g} / \mathrm{dL}-1$ ) observed in the patient at the first admission can be seen due to erythropoietin deficiency in patients with CRF (10). During the follow-up of the patient, decrease in urea-creatinine level with CVVHDF and anuria led us to the diagnosis of CRF.

\section{CONCLUSION}

Chronic renal failure may remain asymptomatic for a long time in young patients (11). If these patients have not been screened before, they usually apply to the hospital in the clinical picture of ARF and they are diagnosed with CRF. Therefore, it should be kept in mind that if an ARF clinical picture is observed in young adults, there may be an ARF picture on the basis of CRF. Also, it should be remembered that there may be a risk of developing CRF in the use of wild tobacco and may lead to the development of ARF.

Informed Consent: Our patient, who was a foreign national, remained in our follow-up only for one day after being extubated, and no communication could be established after he was referred to the another clinic, and therefore no written consent could be obtained.
Peer-review: Internally peer-reviewed.

Author Contributions: Concept - S.S., Ü.Y., Ü.A.T.; Design - S.S.; Supervision - Ü.A.T.; Resources - I.A., Ü.Y.; Materials - I.A.; Data Collection and/or Processing - S.S.; Analysis and/or Interpretation - S.S.; Literature Search - S.S.; Writing Manuscript - S.S.; Critical Review - S.S., Ü.A.T.

Conflict of Interest: The authors have no conflict of interest to declare.

Financial Disclosure: The authors declared that this study has received no financial support.

\section{REFERENCES}

1. Erenmemişoğlu A. Re: Turkish smokeless tobacco "Maras powder". Prev Med 1999; 28: 616-7.

2. Fasanmade A, Kwok E, Newman L. Oral squamous cell carcinoma associated whit khat chewing. Oral Surg Oral Med Oral Pathol Oral Radiol Endod 2007; 104: e53-5.

3. Keten HS, Ölmez S, Üçer H, Işık O, Yıldırım F, Çelik M. Acute effects of Maras powder (smokeless tobacco) on blood pressure and heart rate. Cukurova Med J 2017; 42: 210-5.

4. Neild GH. Primary renal disease in young adults with renal failure. Nephrol Dial Transplant 2010; 25: 1025-32.

5. Kilnet RG, D'Souza RJ, Oliveira DB, MacPhee IA, Turner DR, Eastwood JB. Acute renal failure from intoxication by Cortinarius orellanus: recovery using anti-oxidant therapy and steroids. Nephrol Dial Transplant 1999; 14: 2779-80.

6. Fenves $A Z$, Emmett $M$, White MG. Lithium intoxication associated with acute renal failure. South Med J 1984; 77: 1472-4.

7. Sucakli MH, Ozkan F, Inci MF, Celik M, Keten HS, Bozoglan O. Effects of smokeless tobacco (Maras powder) use on carotid intima media tickness. Med Sci Monit 2013; 19: 859-64.

8. Orth SR, Hallan S. Smoking: A risk factor for progression of chronic kidney disease and for cardiovascular morbidity and mortality in renal patients-absence of evidence or evidence of absence? Clin J Am Soc Nephrol 2008; 3: 226-36.

9. Yakoub R, Habib H, Lahdo A, Ali RA, Varjabedian L, Atalla G, et al. Association between smoking and chronic kidney disease: a case control study BMC Public Health 2010; 10: 731.

10. Babitt JL, Lin HY. Mecanism of Anemia in CKD. J Am Soc Nephrol 2012; 23: $1631-4$

11. Prassher PK, Varma PP. Chronic renal failure-pitfalls in diagnosis Med J Armed Forces India 1997; 53: 295-7. 